\title{
Soft Tissue Facial Profile Changes Associated with Incisors Retraction
}

\author{
Ayman Salman Al-Shakhs and Hayder Abdallah Hashim
}

\section{ABSTRACT}

Background: The general tendency of facial soft tissue response toward incisors retraction could be expected in various malocclusions. However, different initial malocclusion no doubt leads to differences in this response.

Material and method: This retrospective study consisted of thirty-seven pre- and posttreatment lateral cephalographs belongs to adolescent female with mean age of 15.03 years. The twenty-four landmarks (skeletal, dental, soft tissue) were located, and horizontal and vertical reference planes were used. Sixteen linear and six angular measurements were evaluated statistically. The pretreatment and posttreatment lateral cephalograms were superimposed on best fit cribriform plate of the ethmoid to analyze soft tissue facial profile changes after orthodontic treatment.

Results: The three methods of error indicated that measurements were valid and reliable. The Labrale superius retraction exhibited the best predictability among upper lip components $(\mathrm{Sn}, \mathrm{Ss})$, whereas the lower lip showed better predictability and correlation than the upper lip. The upper and the lower lips revealed relatively similar mean retraction value (2.92 $\mathrm{mm})$ and $(2.6 \mathrm{~mm})$ although the upper incisors retracted more $(5.25 \mathrm{~mm})$ than the lower incisors $(2.86 \mathrm{~mm})$.

Conclusion: The upper incisors to Labrale superius ratio (1.99:1, UIP:Ls) exhibited the highest correlation $(r=0.55 * *)$ among the other established ratios. The lower incisors to Labrale inferius ratio was (1.13:1, LIP: Is) with significant correlation $(r=0.44 * *)$, whereas no significant correlation was observed with Labrale superius $(r=0.27)$.

Keywords: Soft tissue profile, upper and lower lip, incisors retaction.
Published Online: June 30, 2020

ISSN: $2736-54$

DoI: 10.24018 /ejclinicmed.2021.2.3.24

Dr. Ayman Salman Al-Shakhs

BDS. MSc., Post graduate candidate, King Saud University, Dental College, Kingdom of Saudi Arabia.

Professor Hayder Abdallah Hashim* BDS, MSc, Hamad medical corporation, Rumaila Hospital, Hamad Dental Centre, Orthodontic División, Qatar.

(e-mail: hahashim78@yahoo.com)

*Corresponding Author

Professor Hayder Abdallah Hashim

Hamad medical corporation, Rumaila hospital, Hamad dental centre, Orthodontic División, Qatar

\section{INTRODUCTION AND REVIEW OF THE LITERATURE}

Few studies were found in the orthodontic literature prior to the 1950's in which an attempt has been made to relate orthodontic treatment to the soft-tissue profile [1].

In one of the first investigations of the soft-tissue profile response to orthodontic treatment, Riedel [2] (1950) studied facial profiles of thirty persons by means of lateral cephalograms. He reported that the relation of the maxillary and mandibular apical bases, the degree of convexity of the skeletal pattern, and the relation of the anterior teeth to their respective apical bases have a marked influence on the softtissue profile. Facial profile often altered through mechanotherapy, but predictability is poor [3].

Burstone [4] presented a method to analyze the soft-tissue profile by means of angular and linear measurements. $\mathrm{He}$ described the average morphology and the variation of acceptable profiles and reported that desirable and undesirable changes in the facial contour could be influenced by the underlying dentoskeletal framework. In a later study, Burstone [5] described in detail the lip posture and its role in orthodontics and proposed the use of the relaxed lip position for taking cephalograms and for treatment planning.

Ricketts [6] advocated a line which he named the "esthetic plane" to describe the relationship of the lips to the soft tissues of the chin and nose. In Caucasian adults, he observed that lips should be contained within this line. The line is drawn from the chin to the tip of the nose. He also noticed that the upper lip thickened $1 \mathrm{~mm}$ with $3 \mathrm{~mm}$ of retraction of the upper incisors, whereas the lower lip curled backward with no thickening.

In 1961, Subtelny [7] demonstrated the effect of orthodontic treatment on the lip position. He presented five patients who showed a change in lip position due to treatment and growth and concluded that lip posture was closely correlated with the posture of the underlying dental and alveolar structures.

In a study of adolescent boys and girls, Bloom [8] found high correlation between maxillary central incisor changes and the superior sulcus, upper and lower lips. He also found strong relationship of the lower incisor to the inferior sulcus and the lower lip and concluded it was possible to predict the perioral soft-tissue profile changes in relation to the expected amount of anterior tooth movement. 
In a similar study, Rudee [9] studied soft tissue changes in eighty-five treated orthodontic patients. He reported that the average ratio of upper incisor retraction to upper lip and lower lip retraction was 2.9:1 and 1:1, respectively. Similarly, the lower incisor to lower lip retraction ratio was 0.59:1. However, his sample was selected regardless of age and sex, and no attempt was made to separate the growth effect from changes due to treatment.

Hershey [10] investigated the effect of incisor retraction on soft-tissue profile changes in thirty-six post adolescent female patients. He concluded that neither the simple nor the multiple correlation coefficients obtained were clinically useful in predicting soft-tissue response from incisor retraction. The same findings were observed by Wisth [11] who studied lip morphology and treatment changes in two groups of boys. He found that the variability of the results was great and concluded that prediction of soft tissue changes in an individual case is impossible, particularly if the overjet is great.

Huggins and McBride [12] did a study on thirty-three randomly selected Class II Division1 patients with overjet ranging from 3.0 to $12.0 \mathrm{~mm}$ without mentioning whether lips were relaxed or closed during radiographic exposure. Their analysis showed that subnasale, labrale superius, and labrale inferius moved nearer to the facial plane as a result of the hard tissue remodeling due to orthodontic treatment. Female patients showed a relationship between the upper incisor retraction and the reduction in prominence of the upper and lower lips. The male patients revealed no correlation between the upper incisor and the lip position. They attributed this to the continued mandibular growth in males.

However, many studies have described a relationship between incisors and lip retraction, but the strength of this relationship varies greatly. It is generally concluded that the relationship between the hard and the soft tissue change is subjected to large individual variations [13].

In attempt to determine the effects of incisor retraction on the profile, several studies were conducted to quantify and to predict the relationship between incisor retraction and lip retraction. Except for one study [7] that found a predictable amount of soft tissue changes in response to incisor retraction, the majority of the studies on both growing and nongrowing subjects concluded that large individual variations preclude accurate prediction in any given person [5], [10]. On the other hand, lip structure seems to have an influence on lip response to incisor retraction.

Oliver [14] found that patients with thin lips or high lip strain displayed a significant correlation between incisor retraction and lip retraction, whereas those with thick lips or low lip strain displayed no such correlation. On the other hand, Wisth [11] noted that lip response, as a proportion of incisor retraction, decreased as the amount of incisor retraction increased. This seems to indicate that the lips have some inherent support. Further, it was observed that upper vermillion height was negatively correlated with the upper lip retraction [15]. However, these changes in the upper vermillion height did not significantly correlate with the magnitude of incisor retraction.

In one study, $95 \%$ of patients had decreased lip protrusion due to the extraction of four premolars, whereas the nasolabial angle increased by $5.2^{\circ}$, the upper lip retracted 3.4 $\mathrm{mm}$ to the E-line, and the lower lip retracted $3.6 \mathrm{~mm}$ to the Eline [16]. It was also found that maxillary incisor retraction led to upper lip retraction, increased lower lip length, and increased the nasolabial angle [17], whereas the mandibular incisor position determined lower lip position and shape [18].

In African Americans study carried out by Caplan and Shivapuja [19] a ratio of 1.2:1 was attained between maxillary incisors retraction and upper lip change, whereas; $(1.75: 1)$ was found between mandibular incisor retraction and retraction of the lower lip $(\mathrm{r}=0.70, \mathrm{P}<0.05)$. On the other hand, a weak relationship was found between upper lip retraction and retraction of the maxillary incisors $(r=0.42$, $\mathrm{P}<0.05)$. They concluded that the mandibular incisor was the only hard tissue variable that could be used as a predictor in a regression model to explain lip response to orthodontic therapy. Further, Conley and Jernigan [20] did study among Caucasians. They reported 2.68:1 ratio of maxillary incisors retraction to upper lip change, which is considerably mild. Furthermore, Lo and Hunter [21] concluded that upper incisors retraction has strong correlation with nasolabial angle (mean ratio of $1.6 \circ$ to $1 \mathrm{~mm}$ ) which if not predicted properly might lead to obtuse nasolabial angle in patients with Class II division 1 malocclusion ending with unpleasing facial profile.

Using maxillary metallic implant superimposition to reduce confounding factors of facial growth, similar ratio of upper lip retraction has been found in both pretreatment lip competent and non-competent groups (0.75:1 \& 0.70:1, respectively). The non-competent group showed more retraction at upper stomium. Nasolabial angle also tends to open after incisor retraction but with less predictability [22].

Orthodontic research dealing with facial structure has shown that hard and soft tissue changes either coincide with each other [2], [10] or not directly related [23], [18]. However, in several studies' horizontal changes in dentoskeletal structure and soft-tissue profile were assessed using a reference line through sella perpendicular to the line Sella-Nasion minus $7^{\circ}$ to approximate the true horizontal [24], [17], [1]. Similarity in the methodology facilitates comparison between these studies.

However, it was reported that care must be considered to preserve the nasolabial angle within $10^{\circ}$ of $100^{\circ}$, where several studies in layperson preferences found that an overly obtuse or acute nasolabial angle is not considered to be aesthetic [25], [26].

Very recently, Hodgkinson [27] stated "Incisor retraction may result in lip retraction, interlabial gap closure and increase of the nasolabial angle but a clear consensus on the effect of incisor retraction on facial aesthetics has not yet been achieved. Despite current evidence being weak, it seems to indicate that in a well-managed orthodontic case, with or without extractions, the soft-tissue and facial aesthetic changes are generally favorable or clinically insignificant".

\section{AIM OF THE STUDY}

To determine the soft tissue facial profile changes associated with upper and lower incisors retraction. 


\section{RESEARCH HYPOTHESIS}

Null Hypothesis (H0): There are no changes in the soft tissue facial profile after incisors retraction.

Alternative Hypothesis (Ha): There are changes in the soft tissue facial profile after incisors retraction.

\section{MATERIALS AND METHOD}

\section{A. The Sample}

The sample of the present study consisted of pretreatment and posttreatment lateral cephalographs taken for thirtyseven orthodontically treated females with a mean age of 15.03 years. They were selected according to the following criteria:

1. Patients with age ranged from 13 to 20 years old.

2. Having pretreatment Class II division 1 malocclusion (skeletal and dental) with:

- ANB $\geq 5^{\circ}$ and/or Wits $>+2 \mathrm{~mm}$;

- At least cusp to cusp molar and canine relationships;

- Overjet $\geq 5 \mathrm{~mm}$.

3. All subjects were treated by one orthodontist with fixed edgewise mechanotherapy with extraction of upper first premolars and lower second premolars.

4. Availability of good quality pre- and posttreatment lateral cephalographs taken by same Cephalostat with the teeth in occlusion and lips in a relaxed position.

5. None of the cases had congenital anomalies, jaw trauma, fractures and significant facial asymmetry.

The average time between pretreatment and posttreatment radiographs was two years and ten months.

\begin{tabular}{llllll}
\multicolumn{6}{c}{ TABLE I: The AgE AT PRETREATMENT } \\
\hline & N & Minimum & Maximum & Mean & SD \\
\hline age & 37 & 13.00 & 20.00 & 15.03 & 2.13 \\
\hline
\end{tabular}

\section{B. Cephalometric Analysis}

The retrospective lateral cephalographs used in the present study were taken using Broadbent [28] standardized cephalometric technique. All cephalographs were taken by the same operator and the same cephalostat. Patients were positioned following Burstone's guidelines [5]:

1. Patient's sagittal plane at right angle to the path of $x$-ray

2. Teeth in maximum intercuspation.

3. Relaxed lips posture.

\section{Cephalometric Analysis Steps}

Manual tracing for each of the 37 pretreatment $\left(\mathrm{T}_{1}\right)$ and posttreatment $\left(\mathrm{T}_{2}\right)$ lateral cephalographs was done by one operator in a darkened room on a fluorescent tracing screen. An acetate papers with 0.003 -inch thickness have been used with $0.5 \mathrm{~mm}$ mechanical black and blue lead pencils for pretreatment and posttreatment tracing respectively at the same time to minimize tracing error.

As shown in Fig. 1, the following fifteen hard tissue and nine soft tissue landmarks were identified according to the classic definitions found in the literature [29], [30]:

\section{- Hard tissue landmarks}

1. (S) Sella, center of the contour of sella turcica.

2. (N). Nasion, Is the most anterior point of the nasofrontal suture in the midsagittal plane.

3. (ANS) Anterior nasal spine, the tip of the median, sharp bony process of the maxilla at the lower margin of the anterior nasal opening.

4. (PNS) Posterior nasal spine, the most posterior point at the sagittal plane on the bony hard palate.

5. (Sp) Spina marked, the intersection points of $\mathrm{N}-\mathrm{Me}$ line and ANS-PNS line.

6. (A) Subspinale, the deepest point in the midsagittal plane between the anterior nasal spine and the alveolar crest.

7. (UIP) Upper incisor point, the most anterior point on the crown of upper incisor.

8. (Is) Incision superius, upper incisor incisal edge.

9. (Isa) Apex of upper central incisor.

10. (Ii) Incision inferius, lower incisor incisal edge.

11. (LIP) Lower incisor point, the most anterior point on the crown of lower incisor.

12. (Iia) Apex of lower central incisor.

13. (B) Supramentale, the deepest point in the midsagittal plane between the alveolar crest and pogonion.

14. (Me) Menton, the most inferior point on the symphyseal outline.

15. (Go) Gonion, the midpoint at the angle of the mandible.

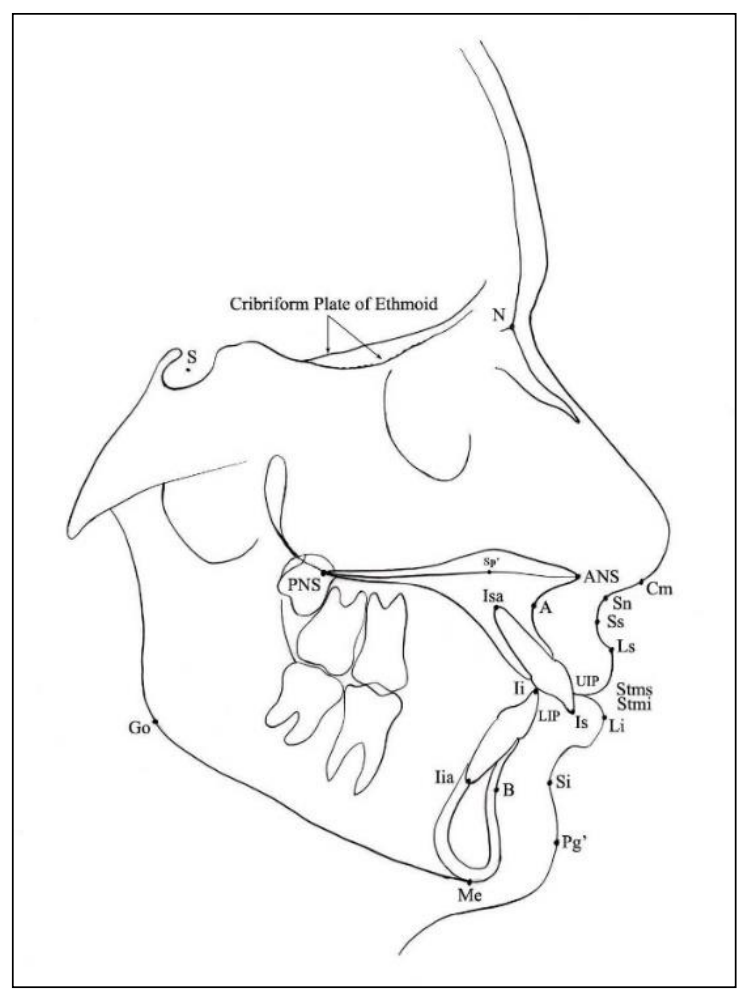

Fig. 1. Cephalometric landmarks.

\section{- Soft tissue landmarks}

1. (Cm) Columella, the most anterior soft tissue points on the columella (nasal septum) of the nose.

2. (Sn) Subnasale, the point of convergence of the nose and the upper lip.

3.(Ss) Sulcus superius, the point of greatest concavity in the midline between the upper lip (Ls) and subnasale (Sn).

4. (Ls) Labrale superius, the most anterior point on the convexity of the upper lip.

5. (Stms) Stomion superius, the lowermost point of the upper lip. 
6. (Stmi) Stomium inferius, the uppermost point on the vermilion border of the lower lip.

7. (Li). Labrale inferius, the most anterior point on the convexity of the lower lip.

8. (Si). Sulcus inferius, Is the point of greatest concavity in the midline between the lower lip and soft tissue pogonion.

9. (Pg.') Soft-tissue pogonion, the most anterior point of the soft-tissue chin.

Horizontal and vertical positional changes of these landmarks were measured in relation to the reference lines drawn on the pretreatment cephalographs (Fig. 2) namely:

a. Constructed Frankfort Horizontal line (CFH) drawn from Sella, at $7^{\circ}$ below Sella-Nasion line.

b. Vertical reference line (VRL) drawn by dropping a perpendicular line to $\mathrm{CFH}$ through S-point.

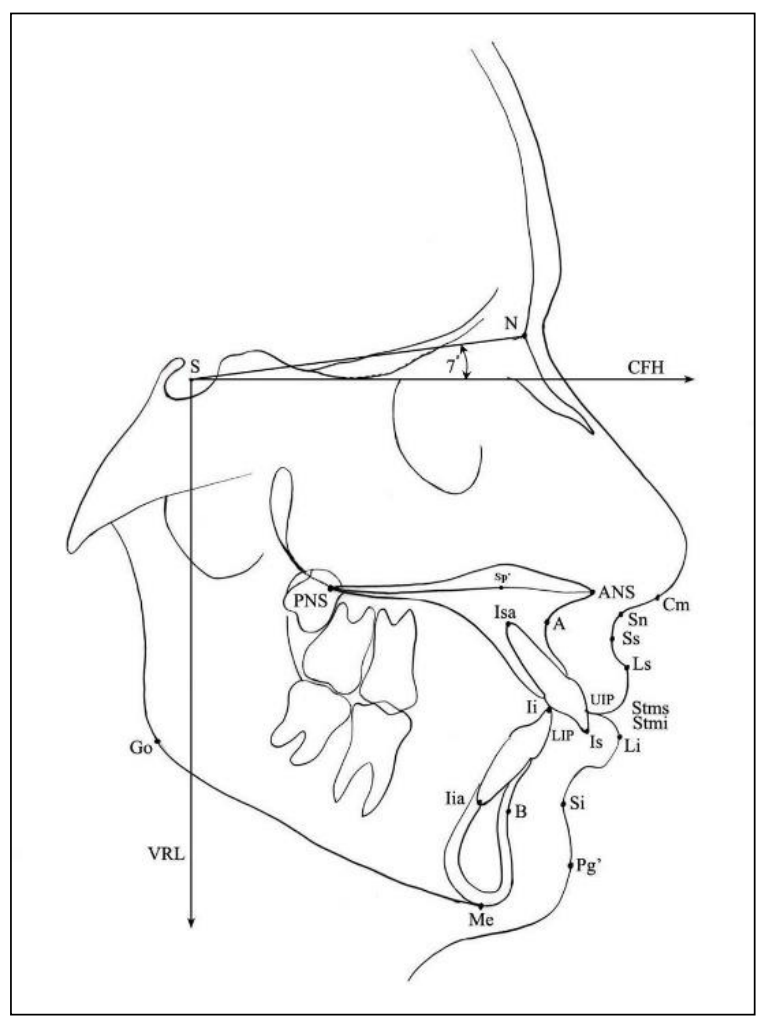

Fig. 2. Constructed Frankfort Horizontal (CFH)and Vertical Reference line (VRL) drawn on pretreatment cephalogram.

Superimposition of pre- and posttreatment cephalograph on the best fit cranial base structures (anterior wall of the Sella turcica, the contours of the cribriform plate, frontoethmoidal crests) as seen in Fig. 3.

Black tracing: pretreatment, Red tracing: posttreatment.

These landmarks used to produce 24 angular and linear measurements, then classified into skeletal, dental, and soft tissue measurements.

Vertical and horizontal displacements of these landmarks were measured; increase in a variable was recorded as a positive and a decrease as a negative. In other words, forward change was recorded as positive and backward change as negative.

Linear measurements were calculated to the nearest 0.5 $\mathrm{mm}$ and to $0.5^{\circ}$ for the angular one. The mean magnification factor (0.8) produced by the Cephalostat was corrected for the linear measurements.

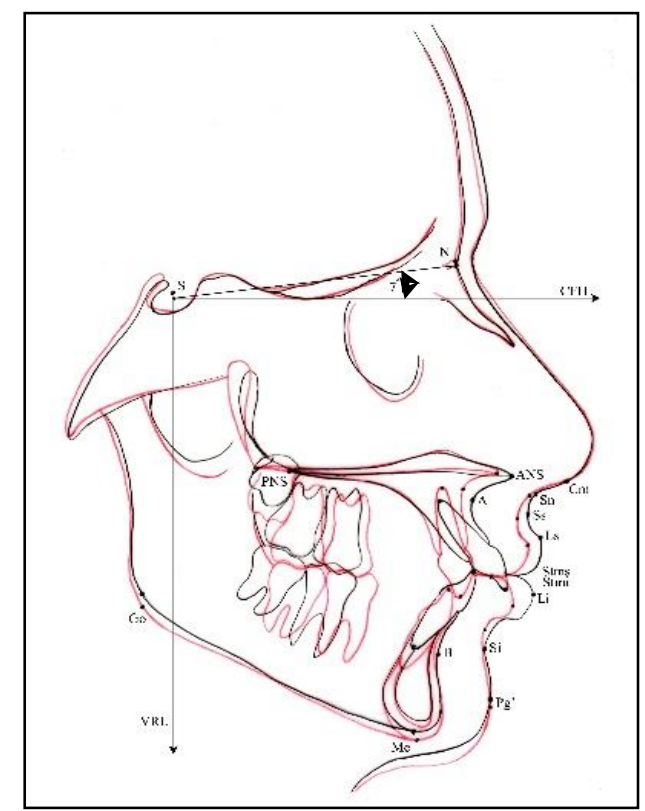

Fig. 3. Superimposition of pre- and posttreatment cephalogram.

\section{Statistical Analysis}

Four skeletal, eight dental and eleven soft tissue cephalometric variables were used to assess treatment changes. The previous measurements were evaluated statistically using Statistical Package Software System, version 12 (SPSS 12). Various analyses have been carried out including descriptive statistics and Student t-test were used for data analysis. Additionally, strength and significance of the relationship between measurements was estimated by Pearson's correlation coefficient (r).

\section{E. Error of the Method}

Prior to the actual recording of the measurements, error due to tracing was assessed. Ten cephalographs were randomly selected and traced twice and retraced after two weeks from the first analysis by the same investigator to determine the intra-examiner error. Error of the method was tested using three methods, Dahlberg's method (SEM is $\leq 1.2$ ), Paired ttest $(>0.05)$ and Correlation coefficient $(r)(r=0.80)$ which showed negligible errors.

\section{RESULTS}

Table II revealing negligible error as followings:

1. Dahlberg's method of error showed that the calculated SEM has a maximum value of 0.74 indicating insignificant standard error of the method (less than1.2).

2. Paired t test has a minimum value of 0.096 indicating also insignificant difference (greater than 0.05 ) between first and second readings.

3. The first and second tracing measurements were highly correlated where the minimum r- value was 0.85 (greater than $0.80)$.

Table III presented the treatment mean changes of the facial soft tissues were and indicated that nasolabial angle (NLA) increased significantly, whereas upper lip angle decreased significantly in relation to $\mathrm{CFH}$ reference line (i.e., both angulations' changes led to significant backward movement of the upper lip). The change in NLA and upper 
lip angle showed large standard deviation value and even more for mentolabial angle (MLA). Upper lip length, on the other hand, did not changed significantly, while thickness reveals significant mean change. Lower lip, on the other hand, displayed different changes; length has increased significantly while thickness did not show significant changes. On the other hand, the uncurling of lower lip increases the mentolabial angle significantly. Moreover, retraction of one or both upper and lower lips resulted in significant reduction of interlabial gap. Nevertheless, all soft tissue variables have shown significant and strong correlation between pre- and posttreatment measurements except lower lip thickness.

Table IV shows the significance of the mean differences between pre- and posttreatment for lower facial height and mandibular inclination in relation to SN line. There was a statistically highly significant mean changes took place in the lower facial height and mandible to SN inclination. Further, the correlations between pre- and posttreatment measurements were very strong and highly significant. Hence, the results indicate that increase in the lower facial height was due to backward rotation of the mandible.

Table V is expressing very high significant dental changes between $\mathrm{T} 1$ and $\mathrm{T} 2$. The upper and lower incisors were retroclined significantly in relation to the Constructed Frankfort horizontal and mandibular plane respectively. Additionally, there were significant and strong correlations between pre- and posttreatment measurements. The overjet was reduced significantly as well as the overbite. Nevertheless, pre- and posttreatment for both were weakly correlated.
TABLE II: THE RESUlTS OF THE THREE ERROR OF THE METHOD TESTS

\begin{tabular}{|c|c|c|c|c|}
\hline No. & Paired variables & $\begin{array}{l}\text { Dahlberg's } \\
\text { method of } \\
\text { error (SEM) }\end{array}$ & $\begin{array}{l}\text { Paired } t \text { - test } \\
(P)\end{array}$ & $\begin{array}{c}\text { Correlation } \\
(r)\end{array}$ \\
\hline 1 & ANB & 0.5 & 0.193 & 0.938 \\
\hline 2 & Wits & 0.33 & 0.096 & 0.949 \\
\hline 3 & Lower facial height & 0.44 & 0.343 & 0.985 \\
\hline 4 & $\begin{array}{l}\text { Mandibular plane } \\
\text { inclination }\end{array}$ & 0.31 & 0.168 & 0.999 \\
\hline 5 & Nasolabial angle & 0.63 & 1.000 & 0.997 \\
\hline 6 & Upper lip angle & 0.63 & 0.509 & 0.997 \\
\hline 7 & Subnasale retraction & 0.22 & 0.343 & 0.895 \\
\hline 8 & $\begin{array}{l}\text { Sulcus superius } \\
\text { retraction }\end{array}$ & 0.2 & 0.591 & 0.926 \\
\hline 9 & Upper lip length & 0.24 & 0.193 & 0.976 \\
\hline 10 & Upper lip thickness & 0.3 & 0.726 & 0.905 \\
\hline 11 & Upper lip retraction & 0.43 & 0.811 & 0.914 \\
\hline 12 & Lower lip length & 0.22 & 0.343 & 0.989 \\
\hline 13 & Lower lip thickness & 0.28 & 0.443 & 0.990 \\
\hline 14 & Lower lip retraction & 0.36 & 0.555 & 0.929 \\
\hline 15 & Mentolabial angle & 0.74 & 0.780 & 0.996 \\
\hline 16 & Interlabial angle & 0.3 & 0.279 & 0.889 \\
\hline 17 & Overjet & 0.24 & 0.678 & 0.855 \\
\hline 18 & Overbite & 0.22 & 0.343 & 0.995 \\
\hline 19 & $\begin{array}{l}\text { Upper incisors } \\
\text { inclination }\end{array}$ & 0.44 & 0.343 & 0.998 \\
\hline 20 & $\begin{array}{l}\text { Upper incisors } \\
\text { retraction }\end{array}$ & 0.1 & 0.343 & 0.995 \\
\hline 21 & $\begin{array}{l}\text { Lower incisors } \\
\text { inclination }\end{array}$ & 0.22 & 0.343 & 0.999 \\
\hline 22 & $\begin{array}{l}\text { Lower incisors } \\
\text { retraction }\end{array}$ & 0.36 & 1.000 & 0.958 \\
\hline 23 & $\begin{array}{l}\text { Upper incisors } \\
\text { intrusion }\end{array}$ & 0.33 & 0.343 & 0.961 \\
\hline 24 & $\begin{array}{l}\text { Lower incisors } \\
\text { intrusion }\end{array}$ & 0.28 & 0.443 & 0.985 \\
\hline
\end{tabular}

TABLE III: SOFT TISSUE CHANGES

\begin{tabular}{|c|c|c|c|c|c|c|c|c|c|c|c|}
\hline & \multirow{2}{*}{ Variable } & \multicolumn{2}{|c|}{$\mathrm{T}_{1}$} & \multicolumn{2}{|c|}{$\mathrm{T}_{2}$} & \multicolumn{2}{|c|}{ M-diff. } & \multirow{2}{*}{ t-value } & \multirow{2}{*}{$P$-value } & \multicolumn{2}{|c|}{ Correlation } \\
\hline & & Mean & $S D$ & Mean & $S D$ & Mean & $S D$ & & & $r$ & $p$ \\
\hline \multirow{8}{*}{ 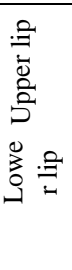 } & -Nasolabial angle & 100.75 & 11.89 & 107.13 & 11.83 & 6.38 & 6.56 & 6.11 & 0.000 & 0.85 & 0.000 \\
\hline & -Upper lip angle & 94.81 & 11.65 & 86.05 & 11.51 & -8.75 & 7.74 & -7.71 & 0.000 & 0.77 & 0.000 \\
\hline & -Upper lip length & 17.2 & 2.05 & 17.34 & 2.28 & 0.14 & 1.52 & 0.56 & 0.57 & 0.76 & 0.000 \\
\hline & -Upper lip thickness & 8.23 & 1.97 & 9.65 & 1.08 & 1.43 & 1.57 & 5.51 & 0.000 & 0.60 & 0.000 \\
\hline & -Lower lip length & 13.38 & 2.07 & 14.04 & 1.63 & 0.66 & 1.62 & 2.47 & 0.018 & 0.64 & 0.000 \\
\hline & -Lower lip thickness & 9.26 & 1.85 & 9.56 & 1.49 & 0.30 & 2.01 & 0.92 & 0.36 & 0.30 & 0.07 \\
\hline & -Mentolabial angle & 115.82 & 17.45 & 122.11 & 16.32 & 6.28 & 13.38 & 2.85 & 0.007 & 0.68 & 0.000 \\
\hline & -Interlabial gap & 1.06 & 1.94 & 0.28 & 0.88 & -0.78 & 1.35 & -3.51 & 0.001 & 0.79 & 0.000 \\
\hline
\end{tabular}

$\mathrm{NS}=$ Not significant, $(*) \mathrm{P}<0.05$ level. $(* *) \mathrm{P}<0.01$ level. $(* * *) \mathrm{P}<0.001$ level.

TABLE IV: SKELETAL CHANGES

\begin{tabular}{|c|c|c|c|c|c|c|c|c|c|c|}
\hline \multirow{2}{*}{ Variable } & \multicolumn{2}{|c|}{$\mathrm{T} 1$} & \multicolumn{2}{|c|}{$\mathrm{T} 2$} & \multicolumn{2}{|c|}{ M-diff. } & \multirow{2}{*}{ t-value } & \multirow{2}{*}{ P-value } & \multicolumn{2}{|c|}{ Correlation } \\
\hline & Mean & SD & Mean & SD & Mean & SD & & & $\mathrm{r}$ & $\mathrm{P}$ \\
\hline $\begin{array}{c}\text { Lower facial } \\
\text { height }\end{array}$ & 53.6 & 3.83 & 54.5 & 4.2 & 0.82 & 1.28 & 3.88 & 0.000 & 0.95 & $0.000 * * *$ \\
\hline $\begin{array}{c}\text { Mandible to } \\
\text { SN } \\
\text { inclination }\end{array}$ & 41.8 & 6.8 & 42.4 & 7.2 & 0.54 & 1.32 & 2.48 & 0.018 & 0.98 & $0.000 * * *$ \\
\hline
\end{tabular}

NS = Not significant, $(*) \mathrm{P}<0.05$ level. $(* *) \mathrm{P}<0.01,(* * *) \mathrm{P}<0.001$

\begin{tabular}{|c|c|c|c|c|c|c|c|c|c|c|}
\hline \multirow{2}{*}{ Variable } & \multicolumn{2}{|c|}{$\mathrm{T} 1$} & \multicolumn{2}{|c|}{$\mathrm{T} 2$} & \multicolumn{2}{|c|}{ M-diff } & \multirow{2}{*}{ T-value } & \multirow{2}{*}{$\begin{array}{c}\mathrm{P} \\
\text { value }\end{array}$} & \multicolumn{2}{|c|}{ Correlation } \\
\hline & Mean & SD & Mean & SD & Mean & SD & & & $\mathrm{r}$ & $\mathrm{P}$ \\
\hline Overjet & 5.2 & 0.79 & 1.78 & 0.69 & -3.42 & 1.21 & -14.7 & 0.000 & 031 & $0.058^{*}$ \\
\hline Overbite & 2.74 & 1.42 & 1.60 & 1.04 & -1.14 & 1.45 & -4.8 & 0.000 & 0.34 & $0.041 *$ \\
\hline $\begin{array}{l}\text { Upper incisor } \\
\text { inclination }\end{array}$ & 115.13 & 7.36 & 101.08 & 9.67 & -14.05 & 8.41 & -10.17 & 0.000 & 0.54 & $0.001 * * *$ \\
\hline $\begin{array}{l}\text { Lower incisor } \\
\text { inclination }\end{array}$ & 100.48 & 6.24 & 95.37 & 5.74 & -5.11 & 6.0 & -5.17 & 0.000 & 0.50 & $0.002 * * *$ \\
\hline
\end{tabular}

$\mathrm{NS}=$ Not significant, $(*) \mathrm{P}<0.05$ level. $(* *) \mathrm{P}<0.01,(* * *) \mathrm{P}<0.001$. 
Table VI representing the different ratios exhibited by the upper and lower lip variables (retraction at subnasale, sulcus superius, labrale superius and labrale inferius) to the upper incisor retraction. The following ratios have been shown:

a) Upper incisor to Subnasale retraction ratio was 5.34:1 which mean that $1 \mathrm{~mm}$ retraction at Subnasale will be resulted from $5.34 \mathrm{~mm}$ retraction of upper incisor. This ratio, on the other hand was statistically at border line $(P=0.05)$ and weakly correlated $(r=0.32)$.

b) Whereas for $1 \mathrm{~mm}$ sulcus superius retraction, require $2.71 \mathrm{~mm}$ upper incisor retraction and the ratio expressed as 2.71:1 (upper incisor to sulcus superius retraction ratio). This ratio was statistically significant at $5 \%$ level.

c) At $1 \%$ level, upper lip retraction at labrale superius by 1 $\mathrm{mm}$ was statistically highly significant and strongly correlated with $1.99 \mathrm{~mm}$ retraction of upper incisor. Hence, upper incisor to labrale superius retraction ratio was 1.99:1.

d) Finally, lower lip retraction at labrale inferius of $1 \mathrm{~mm}$ showed significant correlation with $2.16 \mathrm{~mm}$ upper incisor retraction at $5 \%$ level. Thus, giving a ratio of 2.16:1 (upper incisor to labrale inferius ratio).

Table VII exhibiting the ratios of mandibular incisor retraction to upper lip (at labrale superius) and lower lip (at labrale inferius) retraction. For $1.10 \mathrm{~mm}$ labrale superius retraction, $1 \mathrm{~mm}$ lower incisor retraction would be needed. This ratio of $(1.10: 1)$ lower incisor to labrale superius retraction was statistically insignificant and weakly correlated. On the other hand, statistically high significant and strong correlation was found for the lower incisor to labrale inferius retraction ratio (1.13:1). Thus, $1.13 \mathrm{~mm}$ lower incisor retraction would result in $1 \mathrm{~mm}$ labrale inferius retraction.

\begin{tabular}{|c|c|c|c|c|c|c|c|}
\hline Variables & Cases & Minimum & Maximum & Mean & SD & $\mathrm{r}$ & $\mathrm{p}$ \\
\hline $\begin{array}{l}\text { Upper incisors to subnasale } \\
\text { retraction (UIP/Sn) }\end{array}$ & 34 & 2.50 & 14.00 & 5.34 & 2.75 & 0.32 & $0.054^{*}$ \\
\hline $\begin{array}{l}\text { Upper incisor to sulcus } \\
\text { superius retraction (UIP/Ss) }\end{array}$ & 37 & 1.25 & 7.00 & 2.71 & 1.00 & 0.40 & $0.012 *$ \\
\hline $\begin{array}{l}\text { Upper incisor to labrale } \\
\text { superius retraction (UIP/Ls) }\end{array}$ & 37 & 0.80 & 5.00 & 1.99 & 0.84 & 0.55 & $0.000 * * *$ \\
\hline $\begin{array}{l}\text { Upper incisor to labrale } \\
\text { inferius retraction (UIP/Li) }\end{array}$ & 37 & -1.50 & 8.00 & 2.16 & 1.38 & 0.37 & $0.022 *$ \\
\hline
\end{tabular}

NS = Not significant, $(*) \mathrm{P}<0.05$ level. $(* *) \mathrm{P}<0.01,(* * *) \mathrm{P}<0.001$.

\begin{tabular}{cccccccc}
\multicolumn{2}{c}{ TABLE 7: RATIO OF MANDIBULAR INCISOR RETRACTION TO UPPER AND LOWER LIPS RETRACTION. } \\
\hline Variables & cases & Minimum & Maximum & Mean & SD & r & P \\
\hline $\begin{array}{c}\text { Lower incisor to labrale } \\
\begin{array}{c}\text { superius retraction (LIP/Ls) } \\
\text { Lower incisor to labrale } \\
\text { inferius retraction (LIP/Li) }\end{array}\end{array}$ & 37 & 0.00 & 3.00 & 1.10 & 0.78 & 0.27 & NS \\
\hline
\end{tabular}

NS = Not significant, $(*) \mathrm{P}<0.05 .(* *) \mathrm{P}<0.01,(* * *) \mathrm{P}<0.001$.

\section{DISCUSSION}

The present investigation is a retrospective study designed to evaluate the incisor to lip retraction ratio and the various factor that influence the extent of lips retraction value. The sample consisted of thirty-seven adolescent subjects undergone comprehensive orthodontic treatment. Since most of the soft tissue facial growth changes suggest sexual dimorphism, single gender included only.

Females were chosen as they get matured earlier than males (about 15 years) which minimize the confounding growth effect. Further, a minimum overjet of $5 \mathrm{~mm}$ was selected and at least cusp to cusp molar and canine relationships checked from dental casts. Furthermore, ANB angle should be equal to or greater than 5 degrees and/or Wits appraisal greater than $+2 \mathrm{~mm}$.

Unfortunately, due to these rigid criteria, many cases were excluded. Pretreatment and posttreatment lateral cephalographs have been taken using standardized technique and equipment's as recommended by Battage ${ }^{31}$ and, Isaacson and Thorm [32]. Therefore, all radiographs were of high quality. The high-speed film has been used at fixed distance to the midsagittal plane with restricted head movement.

The different methods of analyses available for evaluating soft tissue profile and the lack of standardization in research methods make it difficult to draw comparisons between results reported by various researchers.
Constructed Frankfort Horizontal (CFH) and vertical reference planes were used to calculate sagittal and vertical changes because of their increased reliability and convenience. Superimposition of pre- and posttreatment cephalographs was applied to minimize growth effect so that discernible treatment changes could be measured. Structural superimposition has been used as advocated by Björk [33] and Björk and Skieller [34] by superimposing the longitudinal radiographs on stable anatomical landmarks, so they fit together in the best way possible.

Several studies report that there is a correlation between incisor retraction and lip retraction, which has been supported by meta-analysis [17], [35], [36].

The Upper and lower incisor point (UIP), the most labial point of the incisor crown, has been used in this study to measure the amount of incisors retraction achieved. Incisal edge (Is) has been the most common landmark selected, but this point has minimal predictive value for lip movement [9],[17]. Additionally, higher determination (64\%) was reported when UIP used [10].

Despite desirable bodily movement during incisors retraction, it is a difficult achievable goal. Frequently, there is a degree of tipping movement (retroclination) accompanying bodily incisors retraction. The mean retraction of upper incisors $(5.25 \mathrm{~mm})$ ends with $14.05^{\circ}$ up-righting relative to $\mathrm{CFH}$ plane. Lower incisors inclination, in Class II division 1 malocclusion, frequently attempts compromised position. Therefore, some proclination would be acceptable, 
and the lesser amount of retraction occurred $(2.86 \mathrm{~mm})$ were concurrent with lower incisors alignment and intrusion. Intrusion was more in lower incisors $(1.42 \mathrm{~mm})$ than upper incisors $(0.23 \mathrm{~mm})$. This intrusion is needed as good number of cases (nine) in the study was in traumatic deep bite (5-6 $\mathrm{mm})$.

In response to incisors retraction, variables of upper lip showed differential changes $(\mathrm{Sn}=1.04 \mathrm{~mm}, \mathrm{Ss}=2.06 \mathrm{~mm}$, $\mathrm{Ls}=2.92 \mathrm{~mm}$ ) with subsequent lip uncurling resulted. These different values were due to different factors, not all of them are well known. Among these the individual response, anatomical complexity and mechanotherapy applied were contributing to these variations.

Furthermore, after incisors retraction, the lower lip was retracted by a mean of $2.60 \mathrm{~mm}$ which is close to upper lip retraction $(2.92 \mathrm{~mm})$ although different degree of upper and lower incisors retraction performed. This might be due to initial everted lower lip posture where it is trapped behind upper incisors. Rains and Nanda ${ }^{1}$ found that the lower lip had more variable than the upper lip to the differences in upper incisors retraction. In contrast, position of the lower lip remains almost unchanged in Talass's et al study [17]. This might be due to mixed extraction and non-extraction therapy applied in his sample.

Several factors influence lower lip retraction, namely upper and lower incisors retraction, lower incisors intrusion and initial lower lip thickness. This is not in line with Rains and Nanda ${ }^{1}$ findings where significant correlation was observed only with mandibular rotation. In the present study, the lower incisors retraction showed greater correlation $\left(\mathrm{r}=0.44^{* *}\right)$ with the lower lip retraction than the upper incisors $(\mathrm{r}=0.37 *)$. Indeed, the lower incisors retraction by one millimeter would result in $0.43 \mathrm{~mm}$ retraction of lower lip. This result is less than the finding reported by Hodges et al. [37]-[39]. They reported that for every millimeter of lower incisor retraction, lower lip retraction ranges from $0.8 \mathrm{~mm}$ to $1.3 \mathrm{~mm}$. This value is close to the lower incisors intrusion, where $(1.00 \mathrm{~mm})$ millimeter incisors intrusion resulted in $(0.3$ $\mathrm{mm}$ ) retraction of lower lip, which again confirms the strong correlation between incisors intrusion and retraction. The result of the present study revealed that the initial lower lip thickness had an important role with lower lip retraction at Labrale inferius.

When the upper and lower incisors being retracted; both upper and lower lips will followed in different ratios. This is due to different method of calculating upper incisors retraction used among different studies. Upper incisor point (UIP) was used in the present study and by Rains and Nanda [1], whereas the Incision superius (Is) was used by Talass et al [17] and Conley and Jernigan [20]. Therefore, comparison between these studies is difficult for the reasons mentioned above.

Significant ratio was obtained $(2.71: 1)$ where $2.71 \mathrm{~mm}$ upper incisors retraction will be required to obtain $1 \mathrm{~mm}$ retraction of Sulcus superius. Lew [40] found almost similar ratio (2.1:1) although lingual orthodontic approach was performed instead of labial orthodontic used in the present study. Further, less ratio (0.14:1) was found by Lo and Hunter [21] in a mixed sample of males and females which might affect the result.

Upper incisors (UIP) to Labrale superius (Ls) retraction ratio: (UIP:Ls) showed the most significant and highest correlation found among other ratios in the present study, Labrale superius undergoes a mean retraction ratio of 1.99:1. This seems very interesting since Labrale superius being the free end of the upper lip, expected to reveal the greatest response to incisors retraction. On the other hand, Rains and Nanda ${ }^{1}$ gave a mean ratio of (1.6:1, Ls: UIP) which is closer to the present study even though fewer upper incisors retraction applied $(3.1 \mathrm{~mm})$. In contrast, Lo and Hunter [21] reported a mean ratio of $(2.5: 1, \mathrm{Ls}$ : Is), and greater $(\mathrm{r}=0.76)$ correlation coefficient than in the present study. Waldman [41] reported greater mean ratio (3.8:1) where different reference planes were used. Talass et. al. [17], however, went to the extreme and reported the highest mean ratio $5: 1$.

The upper incisors (UIP) to Labrale inferius $(\mathrm{Li})$ retraction ratio: (UIP: $\mathrm{Li}$ ) indicated that as upper incisors retraction mainly affects upper lip, the lower lip, on the other hand, could be influenced too. This is true in cases with moderate to severe Class II division 1 malocclusion especially with deep bite as observed in the present study. Everted lower lip often entrapped behind upper incisors. Upon upper incisors retraction, unfolding of lower lip would result with subsequent improvement of lips competency. Consequently, a ratio of $(2.16: 1)$ represents this mutual relationship between upper incisors and lower lip. This agreed with Bloom [8], Rudee [9], Roos [18] and Kusnoto and Kusnoto [42] and disagreed with Hasstedt [43], Ricketts [6] and Lo and Hunter [21]. On the other hand, insignificant correlation was found with Labrale inferius (Li). One reason of this conflicting result might be due to lower lip advancement after lower incisors proclination during treatment.

Further, when investigating the lower incisors to Labrale inferius $(\mathrm{Li})$ retraction ratio, the result of the present study revealed that the lower incisors were retracted $2.86 \mathrm{~mm}$ on average. The ratio obtained (1.13:1) was highly significant at $1 \%$ level. This agreed with Kusnoto and Kusnoto [42] where similar correlation and significance level were reported. Rains and Nanda [1], however, did not establish significant correlation.

Despite the wide variation of facial soft tissue response to the change in underlying hard tissues especially incisors, general tendency of soft tissue following orthodontic treatment are valuable tool clinically for better estimating the expected changes in the soft tissue facial profile. Further, changes in the soft tissue facial profile caused by tooth movement have distinct characteristics which cannot be calculated easily by ratio or formula. Wide variability was shown, nevertheless, a prediction of posttreatment profile change may be still possible. Pretreatment facial soft tissue profile should be evaluated individually. It is important to study the relaxed lip posture due to its accuracy in determining posttreatment posture as Burstone [5] described

Collectively, the above-mentioned soft tissue facial changes could be used to predict the posttreatment facial profile. The amounts of planned incisors retraction must be estimated and drawn on the pretreatment cephalometric tracing then redraw the expected soft tissue movement considering both the direction and amount.

From the above findings, the stated null hypothesis "There are no changes in the soft tissue facial profile after incisors retraction" was rejected and accept the alternative hypothesis 
"There are changes in the soft tissue facial profile after incisors retraction"

\section{CONCLUSIONS}

The Alternative Hypothesis (Ha) that there are changes in the soft tissue facial profile after incisors retraction; was accepted

The following conclusions were drawn:

1. Nasolabial angle significantly increased. However, it is poorly predictable.

2. The mentolabial angle showed weak predictability.

3 . The changes in the interlabial gap have the highest predictability and correlation, making it a more useful clinical tool.

4. The changes in the lower lip thickness have the greatest predictability whereas the change in the length was the least.

5. The upper and the lower lips revealed relatively similar mean retraction value $(2.92 \mathrm{~mm})$ and $(2.60 \mathrm{~mm})$ respectively although the upper incisors retracted more $(5.25 \mathrm{~mm})$ than the lower incisors $(2.86 \mathrm{~mm})$.

6. The upper incisors to Labrale superius ratio was (1.99:1, UIP: Ls) exhibited the highest correlation $\left(\mathrm{r}=0.55^{* *}\right)$ among the other established ratios.

7. The lower incisors to Labrale inferius ratio was (1.13:1, LIP: Is) with significant correlation $(\mathrm{r}=0.44 * *)$, whereas no significant correlation was observed with Labrale superius ( $\mathrm{r}$ $=0.27$ ).

\section{REFERENCES}

[1] Rains MD, Nanda R. Soft tissue changes associated with maxillary incisor retraction. Am J Orthod 1982; 81:481-8.

[2] Riedel R. Esthetics and its relation to orthodontic therapy, Angle Orthod. 1950; 20: 168-

[3] O'Reilly WC. Proportional Changes of Hard and Soft Tissue Profiles as a Result of Orthodontic Treatment, M.S. Thesis, University of Washington, 1957

[4] Burstone CJ. The integumental profile. Am J Orthod. 1958; 44: 1-25.

[5] Burstone CJ. Lip posture and its significance in treatment planning. Am J Orthod. 1967; 53: 262-332.

[6] Ricketts RM. Foundation for cephalometric communication. Am J Orthod. 1960; 46: 330.

[7] Subtelny JD. The soft tissue profile, growth and treatment changes, Angle Orthod. 1961; 31: 105-122.

[8] Bloom LA. Perioral profile changes in orthodontic treatment. Am J Orthod. 1961; 47:371.

[9] Rudee DA. Proportional profile changes concurrent with orthodontic therapy. Am J Orthod. 1964; 50: 421-434.

[10] Hershey HG. Incisor tooth retraction and subsequent profile change in postadolescent female patients, AM. J. ORTHOD. 1972; 61: 45-54.

[11] Wisth PJ. Soft tissue response to upper incisor retraction in boys. Br J Orthod 1974; 1:199-204.

[12] Huggins DG, McBride LJ. The influence of the upper incisor position on soft tissue facial profile. Br. J. Orthod. 1975; 2: 141-146.

[13] Zierhut EC, Joondeph DR, Artun J, Little RM. Long-term changes associated with successfully treated extraction and nonextraction Class II Division1 Malocclusions. Angle Orthod. 2000 Jun; 70(3):208-19.

[14] Oliver BM. The influence of lip thickness and strain on upper lip response to incisor retraction. Am J Orthod 1982; 82:141-8.

[15] Perkins RA, Staley RN. Change in lip vermillion height during orthodontic treatment. [Thesis] Iowa City: University of Iowa, 1987.

[16] Drobocky OB, Smith RJ. Changes in facial profile during orthodontic treatment with extraction of four first premolars. Am J Orthod. 1989; 95:220-30.
[17] Talaas MF, Talaas L, Baker RC. Soft-tissue changes resulting from retraction of maxillary incisors. Am J Orthod. 1987; 91:385-94.

[18] Roos N. Soft tissue profile changes in class II treatment. Am J Orthod 1977; 72:165-75.

[19] Caplan MJ, Shivapuja PK. The effect of premolar extractions on the soft tissue profile in adult African American females. Angle Orthod 1997; 129-36.

[20] Conley RS, Jernigan C. Soft Tissue Changes after Upper Premolar Extraction in Class II Camouflage Therapy. Angle Orthod 2006; 76:59-65

[21] Lo FD, Hunter WS. Changes in nasolabial angle related to maxillary incisor retraction. Am J Orthod. 1982; 82:384-391.

[22] Ramos AL, Sakima MT, Pinto ADS, Bowman SJ. Upper Lip Changes Correlated to Maxillary Incisor Retraction- A Metallic Implant Study. Angle Orthod 2005; 75:499-505.

[23] Wylie WL. The mandibular incisor-its role in facial esthetics. Angle Orthod. 1955; 25:32-41.

[24] Tan TJ. Profile changes following orthodontic correction of bimaxillary protrusion with preadjusted edgewise appliance. Int J Adult Orthod Orthognath Surg 1996; 11: 239-51.

[25] Armijo BS, Brown M and Guyuron B (2012) Defining the ideal nasolabial angle. Plastic and Reconstructive Surgery 129: 759-764.

[26] Sinno HH, Markarian MK, Ibrahim AM, et al. (2014) The ideal nasolabial angle in rhinoplasty: a preference analysis of the general population. Plastic and Reconstructive Surgery 134: 201-210.

[27] Danielle Hodgkinson, Fiona A Firth and Mauro Farella. Effect of incisor retraction on facial aesthetics. Journal of Orthodontics; 2019; 1 -5 .

[28] Broadbent BH. A new x-ray technique and its application to orthodontia. Angle Orthod 1931; 1:45-66.

[29] Meredith HW, Chadha JM. A roentgenographic study of change in head height during childhood and adolescence. Hum. Biol 1962; 34:299-319.

[30] Riolo ML, Moyers RE, McNamara JA, Hunter WS. An atlas of craniofacial growth: cephalometric standards from the university school growth study. Ann Arbor: University of Michigan, 1974.

[31] Battagel JM. A comparative assessment of cephalometric errors. Eur J Orthod 1993b; 53:305-314.

[32] Isaacson KG, Thom AR. Orthodontics radiographs guidelines. Brt Orthod Soc, 2001

[33] Björk A. Sutural growth of the upper face studied by the implant method. Acta Odonto. Scand 1966; 24: 109-127.

[34] Björk A, Skieller V. Normal and abnormal growth of the mandible. A synthesis of longitudinal cephalometric implant studies over a period of 25 years. Eur J Orthod 1983; 5:1-46.

[35] Konstantonis D, Vasileiou D, Papageorgiou SN, et al. (2018) Soft tissue changes following extraction vs. nonextraction orthodontic fixed appliance treatment: a systematic review and meta-analysis. European Journal of Oral Sciences 126: 167-179.

[36] Kuhn M, Markic G, Doulis I, et al. Effect of different incisor movements on the soft tissue profile measured in reference to a roughsurfaced palatal implant. American Journal of Orthodontics and Dentofacial Orthopedics. 2016; 149: 349-357.

[37] Hodges A, Rossouw PE, Campbell PM, et al. Prediction of lip response to four first premolar extractions in white female adolescentsand adults. Angle Orthodontist 2009; 79: 413-421.

[38] Kasai K, Soft tissue adaptability to hard tissues in facial profiles. American Journal of Orthodontics and Dentofacial Orthopedics 1998 113: 674-684

[39] Solem RC, Marasco R, Guiterrez-Pulido L, et al. Three dimensional soft-tissue and hard-tissue changes in the treatment of bimaxillary protrusion. American Journal of Orthodontics and Dentofacia Orthopedics. 2013; 144: 218-228.

[40] Lew K. Profile changes following orthodontic treatment of bimaxillary protrusion in adults with Beg appliance. Eur J Orthod 1989; 11:375-81.

[41] Waldman BH. Change in lip contour with maxillary incisor retraction Angle Orthod. 1982; 52:129-34.

[42] Kusnoto J, Kusnoto H. The effect of anterior tooth retraction on lip position of orthodontically treated adult Indonesians. Am J Orthod 2001; 120:304-7.

[43] Hasstedt, CW. A serial cephalometric study of the effects of orthodontic treatment on incisor overbite and soft tissue profile, master's thesis, University of Washington, 1956. 